\title{
To Compare the Effectiveness of Traditional Anterior Colporrhaphy, Posterior Colpoperineorrhaphy with Site-specific Anterior and Posterior Repair for Pelvic Organ Prolapse
}

\author{
${ }^{1}$ Anuja V Bhalerao, ${ }^{2}$ Amishi Vora, ${ }^{3}$ Krutika Bhalerao, ${ }^{4}$ Richa Garg
}

\begin{abstract}
Background: Pelvic organ prolapse (POP) is a common health problem affecting $40 \%$ multiparous women above 35 years of age. Lifetime risk of women requiring surgery for recurrence is $10 \%$. The POP is intricious due to complex pelvic anatomy, and difficulty increases due to tissue weakness, lack of evidence-based surgical guidelines, and lack of standardized definition for surgical success, which results in highly variable estimates of success.
\end{abstract}

Aim: To compare the effectiveness of traditional anteroposterior repair with site-specific repair with concomitant vaginal hysterectomy with respect to anatomical considerations by POP-Q and functional or symptomatic considerations, complications, duration of surgery, and recurrence.

Materials and methods: This hospital-based randomized controlled trial was carried out at a tertiary care hospital from January 1, 2013 to December 31, 2015 over a period of 3 years after obtaining ethical committee approval. All women attending the gynecological outpatient department having symptoms of mass coming out of vagina were subjected to detailed history and examination and 51 women underwent traditional anterior and posterior repair and 44 women underwent site-specific repair with concomitant hysterectomy, with random sampling according to computerized sheet. The effectiveness of both the surgeries was assessed and compared.

Observations: There was statistically significant improvement in all the sites of POP-Q points using traditional repair and sitespecific repair. When compared, site-specific repair by POP-Q was better than traditional method.

Conclusion: Site-specific repair of decussated natural tissue has great curative potential, and success is attributable to site-specific repair, rather than nonspecific scar formation by traditional method. Thus, it is important to properly quantify the repair to be done, whether anterior or posterior, and perform site-specific repair.

Keywords: Pelvic organ prolapse, Site specific repair, Traditional repair.

\footnotetext{
${ }^{1}$ Associate Professor, ${ }^{2}$ Junior Resident, ${ }^{3}$ Intern, ${ }^{4}$ Senior Resident

${ }^{1-4}$ Department of Obstetrics and Gynecology, NKP Salve Institute of Medical Sciences \& Research Center, Nagpur, Maharashtra India

Corresponding Author: Anuja V Bhalerao, Associate Professor Department of Obstetrics and Gynecology, NKP Salve Institute of Medical Sciences \& Research Center, Nagpur, Maharashtra India, Phone: +917122427026, e-mail: anuja_bhalerao@yahoo. com
}

How to cite this article: Bhalerao AV, Vora A, Bhalerao K, Garg R. To Compare the Effectiveness of Traditional Anterior Colporrhaphy, Posterior Colpoperineorrhaphy with Site-specific Anterior and Posterior Repair for Pelvic Organ Prolapse. J South Asian Feder Menopause Soc 2017;5(2):92-98.

Source of support: Nil

Conflict of interest: None

Date of received: 11 June 2017

Date of acceptance: 2 August 2017

Date of publication: December 2017

\section{INTRODUCTION}

Pelvic organ prolapse is a common health problem affecting $40 \%$ multiparous women above 35 years of age, and the lifetime risk of women requiring surgery for recurrence of POP is $10 \%$.

Pelvic organ prolapse affects psychological aspects, sexual behavior and, thus, quality of life. Etiology is thought to be multifactorial for POP. The treatment has evolved from antiquity to today. Women with symptomatic POP have bladder, bowel discomfort, as well as problems with sexual function. Reconstructive surgery for women with prolapse consists of some combination of resuspension of the vaginal apex and anterior and posterior vaginal walls. The choice of a primary surgical procedure for women with POP depends upon a variety of considerations, including the anatomic site of prolapse, presence of urinary or fecal incontinence, health status, and patient preferences.

The POP is intricious due to complex pelvic anatomy, and difficulty increases with time and tissue weakness; absence of evidence-based surgical guidelines and lack of standardized definition for surgical success result in highly variable estimates of success.

This has significant impacts on the ability to conduct, compare, and contrast clinical research in this area. Success of any reconstructive surgery depends on functional resolution of symptoms and anatomic resolution (in operated and unoperated compartments). ${ }^{1}$

Even today, there are no evidence-based guidelines to advice clinicians which surgical intervention to choose, thus letting the clinician in a quandary. 


\section{AIMS AND OBJECTIVES}

To compare the effectiveness of traditional anteroposterior repair with site-specific repair with concomitant vaginal hysterectomy with respect to anatomical considerations by POP-Q and functional or symptomatic considerations, complications, duration of surgery, and recurrence.

\section{MATERIALS AND METHODS}

This hospital-based randomized controlled trial was carried out at a tertiary care hospital from January 1, 2013 to December 31, 2015 over a period of 3 years after obtaining ethical committee approval. All women attending gynecological outpatient department having symptom of mass coming out of vagina were subjected to detailed history pertaining to demographic data, duration of prolapse, urinary symptoms as urgency, frequency, stress urinary incontinence, bowel symptoms as incomplete evacuation of bowel, dyspareunia, etc., affecting quality of life.

Detailed obstetric history mentioning parity, frequency of childbirth, duration of labor, baby size, instrumentation, and postpartum rehabilitation was asked for.

Menstrual history, family history of prolapse, history of precipitating factors as chronic cough, constipation, and mass in abdomen were also asked for. After thorough general examination, per abdomen, cardiovascular system, and respiratory system examination, detailed local examination was done to know the level of vaginal prolapse, stage of prolapse, and thus the deficiency was assessed by per speculum, per vaginum, and per rectal examinations and POP-Q staging.

Women with POP were subjected to investigations and surgery was decided depending on the age, level, compartment, and the stage of prolapse.

The surgery was done by two surgeons of the same experience and skill.

Type of surgery (vaginal hysterectomy with traditional anteroposterior repair and site-specific repair) to be done for women with POP was selected by block randomization (computerized sheet). Totally, 44 women underwent site-specific repair and 51 women underwent traditional method.

Anterior site-specific repair was according to the central, lateral, transverse defects in pubovesicovaginal fascia; posterior defects were classified as detachment of uterosacrals from rectovaginal septum, detachment of perineal body, and tears in rectovaginal septum.

Following observations were made for effectiveness of surgery by comparison of preoperative and postoperative POP-Q and duration of surgery; complications, such as hemorrhage, injury to bladder and bowel, infection, and secondary hemorrhage were also looked for.
After the completion of the surgery, the effectiveness was judged by anatomical consideration of all nine points of POP-Q, and functional efficacy was judged by asking regarding relief of symptoms by a structured validated questionnaire.

Anterior colporrhaphy is plication of fibromuscular layer of vagina to reduce prolapse and support bladder. Posterior colpoperineorrhaphy is plication of fibromuscular layer with inclusion of levator ani and repair of introitus by plication of superficial muscles to perineal body.

Site-specific repair is identification of defect in pubocervical fascia and tear in rectovaginal septum, decussation, and tearing of uterosacrals from perineal body and suturing the torn native tissue.

Women were kept under follow-up for 1 year. Anatomical success was defined if the descent of point $c$ or vault was stage 0 or stage I. Appearance of bothersome symptoms and clinical descent of vault more than stage II after 6 months was labeled as treatment failure and retreatment options were advised, done, and their outcome was noted.

\section{Inclusion Criteria}

- All women with POP in reproductive, perimenopausal, and postmenopausal age groups.

- Women with prolapse willing for follow-up.

\section{Exclusion Criteria}

- Women with POP unfit for surgery.

- Women wanting conservative treatment.

Statistical analysis was done by sample statistics using paired and unpaired " $\mathrm{t}$ " testing using EP1 INFO software version 6, level of significance $=0.05$.

\section{OBSERVATIONS}

In the present study, the mean age of women in traditional repair was 51.41 years and in the site-specific repair group, it was 49.84 years. Most of the women were para 3 and more in both the groups [S-19/44(32.2\%),T-35/51(64.8)] and had level II stage III, IV POP [S-III-46.7\%, IV—45.0\%; T-III-53.3\%, IV-55\%]; multicompartment defect was predominant feature in both the groups.

There was statistically significant improvement in all the sites of POP-Q points using traditional repair (Table 1).

There was statistically significant improvement in all the sites of POP-Q points using site-specific repair (Table 2).

Except for total vaginal length, all the POP-Q points showed statistically significant improvement anatomically when traditional method of repair was used for treatment 
Table 1: Effectiveness of traditional repair of POP

\begin{tabular}{|c|c|c|c|c|c|c|}
\hline \multicolumn{7}{|c|}{ Paired sample statistics (traditional) $n=44$} \\
\hline & & Mean & Standard deviation & Standard error mean & $r$-value & $p$-value \\
\hline \multirow[t]{2}{*}{ Pair 1} & POP-Q preoperative in $\mathrm{cm} \mathrm{Aa}$ & 1.91 & 0.984 & 0.148 & 22.02 & $<0.001$ \\
\hline & POP-Q postoperative anatomical $\mathrm{Aa}$ & -2.32 & 0.883 & 0.133 & & \\
\hline \multirow[t]{2}{*}{ Pair 2} & POP-Q preoperative in $\mathrm{cm} \mathrm{Ba}$ & 3.43 & 1.265 & 0.191 & 23.98 & $<0.001$ \\
\hline & POP-Q postoperative anatomical $\mathrm{Ba}$ & -1.59 & 0.726 & 0.109 & & \\
\hline \multirow[t]{2}{*}{ Pair 3} & POP-Q preoperative in $\mathrm{cm} \mathrm{C}$ & 3.80 & 1.407 & 0.212 & 33.56 & $<0.001$ \\
\hline & POP-Q postoperative C & -4.43 & 0.789 & 0.119 & & \\
\hline \multirow[t]{2}{*}{ Pair 4} & POP-Q preoperative in $\mathrm{cm} \mathrm{Ap}$ & 0.98 & 10.607 & 0.242 & 12.02 & $<0.001$ \\
\hline & POP-Q postoperative anatomical Ap & -2.27 & 0.845 & 0.127 & & \\
\hline \multirow[t]{2}{*}{ Pair 5} & POP-Q preoperative in $\mathrm{cm} \mathrm{Bp}$ & 1.11 & 1.895 & 0.286 & 8.62 & $<0.001$ \\
\hline & POP-Q postoperative anatomical Bp & -1.55 & 0.504 & 0.076 & & \\
\hline \multirow[t]{2}{*}{ Pair 6} & POP-Q preoperative in cm D & -1.42 & 2.913 & 0.444 & 11.65 & $<0.001$ \\
\hline & POP-Q postoperative anatomical D & -7.00 & 1.000 & 0.152 & & \\
\hline \multirow[t]{2}{*}{ Pair 7} & POP-Q preoperative in $\mathrm{cm} T V L$ & 7.93 & 1.087 & 0.164 & -2.11 & 0.040 \\
\hline & POP-Q postoperative anatomical TVL & 8.34 & 0.834 & 0.126 & & \\
\hline \multirow[t]{2}{*}{ Pair 8} & POP-Q preoperative in cm PB & 3.10 & 1.015 & 0.153 & -2.71 & 0.009 \\
\hline & POP-Q postoperative anatomical PB & 3.56 & 0.497 & 0.075 & & \\
\hline \multirow[t]{2}{*}{ Pair 9} & POP-Q preoperative in $\mathrm{cm} \mathrm{Gh}$ & 4.74 & 0.332 & 0.050 & -4.15 & 0.000 \\
\hline & POP-Q postoperative anatomical Gh & 4.98 & 0.151 & 0.023 & & \\
\hline
\end{tabular}

TVL: Total vaginal length; AaBa: Anterior points on vaginal wall; ApBp: Points on posterior vaginal wall; C: Cervix; D: Pouch of douglas; Pb: Perineal body; Gh: Genital hiatus

Table 2: Effectiveness of traditional repair of POP

\begin{tabular}{|c|c|c|c|c|c|c|}
\hline \multicolumn{7}{|c|}{ Paired sample statistics (SSR) } \\
\hline & & Mean & Standard deviation & Standard error Mean & $t$-value & $p$-value \\
\hline \multirow[t]{2}{*}{ Pair 1} & POP-Q preoperative in $\mathrm{cm} \mathrm{Aa}$ & 1.90 & 0.964 & 0.135 & 29.58 & $<0.001$ \\
\hline & POP-Q postoperative anatomical Aa & -1.94 & 0.881 & 0.123 & & \\
\hline \multirow[t]{2}{*}{ Pair 2} & POP-Q preoperative in $\mathrm{cm} \mathrm{Ba}$ & 3.18 & 1.228 & 0.172 & 22.71 & $<0.001$ \\
\hline & POP-Q postoperative anatomical Ba & -1.18 & 0.654 & 0.092 & & \\
\hline \multirow[t]{2}{*}{ Pair 3} & POP-Q preoperative in $\mathrm{cm} \mathrm{C}$ & 3.82 & 1.090 & 0.153 & 35.02 & $<0.001$ \\
\hline & POP-Q postoperative C & -3.41 & 1.388 & 0.194 & & \\
\hline \multirow[t]{2}{*}{ Pair 4} & POP-Q preoperative in $\mathrm{cm} \mathrm{Ap}$ & 0.88 & 1.291 & 0.181 & 12.99 & $<0.001$ \\
\hline & POP-Q postoperative anatomical Ap & -1.80 & 0.849 & 0.119 & & \\
\hline \multirow[t]{2}{*}{ Pair 5} & POP-Q preoperative in $\mathrm{cm} \mathrm{Bp}$ & 1.06 & 1.748 & 0.245 & 9.16 & $<0.001$ \\
\hline & POP-Q postoperative anatomical Bp & -1.27 & 0.451 & 0.063 & & \\
\hline \multirow[t]{2}{*}{ Pair 6} & POP-Q preoperative in cm D & -1.12 & 2.776 & 0.389 & 8.44 & $<0.001$ \\
\hline & POP-Q postoperative anatomical D & -5.37 & 3.033 & 0.425 & & \\
\hline \multirow[t]{2}{*}{ Pair 7} & POP-Q preoperative in $\mathrm{cm}$ TVL & 8.10 & 0.964 & 0.135 & -2.02 & 0.049 \\
\hline & POP-Q postoperative anatomical TVL & 8.43 & 1.204 & 0.169 & & \\
\hline \multirow[t]{2}{*}{ Pair 8} & POP-Q preoperative in cm PB & 3.16 & 1.062 & 0.150 & -3.807 & $<0.001$ \\
\hline & POP-Q postoperative anatomical PB & 3.75 & 0.420 & 0.059 & & \\
\hline \multirow[t]{2}{*}{ Pair 9} & POP-Q preoperative in $\mathrm{cm} \mathrm{Gh}$ & 4.75 & 0.379 & 0.053 & -3.20 & $<0.001$ \\
\hline & POP-Q post-op anatomical Gh & 4.94 & 0.238 & 0.033 & & \\
\hline
\end{tabular}

TVL: Total vaginal length; AaBa: Anterior points on vaginal wall; ApBp: Points on posterior vaginal wall; C: Cervix; D: Pouch of douglas; Pb: Perineal body; Gh: Genital hiatus

of POP as compared with site-specific repair. The sitespecific repair is a better method of repair for POP (Tables 3 and 4).

Functional improvement in quality of life by improvement in symptoms was seen in women who underwent site-specific repair $(29 / 44 ; 65.90 \%)$ than traditional repair $(28 / 51 ; 54.90 \%)$ (Table 5).

There was no statistically significant variation in time required ( $\mathrm{T}=77.31$ minutes, $\mathrm{S}=81.34$ minutes) for doing both types of surgeries (Table 6).

Complications, such as primary hemorrhage, infection postoperatively of the vault, injury to bladder was seen in only 3/95 women who underwent any type of repair for prolapse.

Recurrence (vault prolapse) was seen in $4 / 51$ ( $7.84 \%)$ women who underwent traditional repair and in 2/44 $(4.54 \%)$ who underwent site-specific repair for POP. Totally, 4 women with vault prolapse were treated by abdominal sacrocolpopexy and 2 women underwent high uterosacral ligament suspension.

\section{DISCUSSION}

The anatomic and functional success of site-specific repair of anterior and posterior vaginal wall prolapse was 
Comparing Colporrhaphy, Colpoperineorrhaphy with Anterior and Posterior POP Repair

Table 3: Comparison of traditional repair and site-specific repair of POP (preoperative)

\begin{tabular}{|c|c|c|c|c|c|c|c|}
\hline \multicolumn{8}{|c|}{ Group statistics (preoperative) } \\
\hline & Group & $n$ & Mean & Standard deviation & Standard error mean & $t$-value & $p$-value \\
\hline \multirow[t]{2}{*}{ POP-Q pre-op in cm Aa } & $\mathrm{T}$ & 51 & 1.90 & 0.964 & 0.135 & -0.036 & 00.972 \\
\hline & $S$ & 44 & 1.91 & 0.984 & 0.148 & & \\
\hline \multirow[t]{2}{*}{$P O P-Q$ pre-op in cm Ba } & $\mathrm{T}$ & 51 & 3.18 & 1.228 & 0.172 & -0.997 & 0.322 \\
\hline & S & 44 & 3.43 & 1.265 & 0.191 & & \\
\hline \multirow[t]{2}{*}{$P O P-Q$ pre-op in cm C } & $\mathrm{T}$ & 51 & 3.82 & 1.090 & 0.153 & 0.109 & 0.913 \\
\hline & $S$ & 44 & 3.80 & 1.407 & 0.212 & & \\
\hline \multirow[t]{2}{*}{$P O P-Q$ pre-op in cm Ap } & $\mathrm{T}$ & 51 & 0.88 & 1.291 & 0.181 & -0.319 & 0.75 \\
\hline & $S$ & 44 & 0.98 & 1.607 & 0.242 & & \\
\hline \multirow[t]{2}{*}{$P O P-Q$ pre-op in cm Bp } & $\mathrm{T}$ & 51 & 1.06 & 1.748 & 0.245 & -0.147 & 0.884 \\
\hline & S & 44 & 1.11 & 1.895 & 0.286 & & \\
\hline \multirow[t]{2}{*}{ POP-Q pre-op in cm D } & $\mathrm{T}$ & 51 & -1.12 & 2.776 & 0.389 & 0.381 & 0.704 \\
\hline & S & 44 & -1.34 & 2.925 & 0.441 & & \\
\hline \multirow[t]{2}{*}{ POP-Q pre-op in cm TVL } & $\mathrm{T}$ & 51 & 8.10 & 0.964 & 0.135 & 0.790 & 0.432 \\
\hline & $S$ & 44 & 7.93 & 1.087 & 0.164 & & \\
\hline \multirow[t]{2}{*}{ POP-Q pre-op in cm PB } & $\mathrm{T}$ & 50 & 3.16 & 1.062 & 0.150 & 0.92 & 0.789 \\
\hline & S & 44 & 3.10 & 1.015 & 0.153 & & \\
\hline \multirow[t]{2}{*}{ POP-Q pre-op in cm Gh } & $\mathrm{T}$ & 51 & 4.75 & 0.379 & 0.053 & 0.088 & 0.930 \\
\hline & S & 44 & 4.74 & 0.332 & 0.050 & & \\
\hline
\end{tabular}

TVL: Total vaginal length; AaBa: Anterior points on vaginal wall; ApBp: Points on posterior vaginal wall; C: Cervix; D: Pouch of douglas; Pb: Perineal body; Gh: Genital hiatus

Table 4: Comparison of traditional repair and site-specific repair of POP (postoperative)

\begin{tabular}{|c|c|c|c|c|c|c|c|}
\hline \multicolumn{8}{|c|}{ Group statistics (postoperative) } \\
\hline & Group & $n$ & Mean & Standard deviation & Standard error mean & $t$-value & $p$-value \\
\hline \multirow[t]{2}{*}{ POP-Q post-op anatomical Aa } & $T$ & 51 & -1.94 & 0.881 & 0.123 & 2.077 & 0.041 \\
\hline & S & 44 & -2.32 & 0.883 & 0.133 & & \\
\hline \multirow[t]{2}{*}{ POP-Q post-op anatomical Ap } & $\mathrm{T}$ & 51 & -1.80 & 0.849 & 0.119 & 2.689 & 0.008 \\
\hline & S & 44 & -2.27 & 0.845 & 0.127 & & \\
\hline \multirow[t]{2}{*}{ POP-Q post-op C } & $\mathrm{T}$ & 51 & -3.41 & 1.388 & 0.194 & 4.308 & 0 \\
\hline & S & 44 & -4.43 & 0.789 & 0.119 & & \\
\hline \multirow[t]{2}{*}{ POP-Q post-op anatomical Ba } & $\mathrm{T}$ & 51 & -1.18 & 0.654 & 0.092 & 2.927 & 0.004 \\
\hline & S & 44 & -1.59 & 0.726 & 0.109 & & \\
\hline \multirow[t]{2}{*}{ POP-Q post-op anatomical Bp } & $\mathrm{T}$ & 51 & -1.27 & 0.451 & 0.063 & 2.767 & 0.007 \\
\hline & S & 44 & -1.55 & 0.504 & 0.076 & & \\
\hline \multirow[t]{2}{*}{ POP-Q post-op anatomical TVL } & $\mathrm{T}$ & 51 & 8.43 & 1.204 & 0.169 & 0.419 & 0.676 \\
\hline & S & 44 & 8.34 & 0.834 & 0.126 & & \\
\hline \multirow[t]{2}{*}{ POP-Q post-op anatomical PB } & $\mathrm{T}$ & 51 & 3.75 & 0.417 & 0.058 & 2.114 & 0.037 \\
\hline & S & 44 & 3.56 & 0.497 & 0.075 & & \\
\hline \multirow[t]{2}{*}{ POP-Q post-op anatomical D } & $\mathrm{T}$ & 51 & -5.37 & 3.033 & 0.425 & 3.365 & 0.001 \\
\hline & $S$ & 43 & -7.00 & 1.000 & 0.152 & & \\
\hline \multirow[t]{2}{*}{ POP-Q post-op anatomical Gh } & $\mathrm{T}$ & 51 & 4.94 & 0.238 & 0.033 & -0.868 & 0.388 \\
\hline & S & 44 & 4.98 & 0.151 & 0.023 & & \\
\hline
\end{tabular}

TVL: Total vaginal length; AaBa: Anterior points on vaginal wall; ApBp: Points on posterior vaginal wall; C: Cervix; D: Pouch of douglas; Pb: Perineal body; Gh: Genital hiatus

Table 5: Comparison of traditional repair and site-specific repair of POP in terms of functional improvement of symptoms and quality of life by validated questionnaire

\begin{tabular}{|c|c|c|c|c|c|}
\hline \multicolumn{6}{|c|}{ Functional improvement yes/no *Group cross-tabulation } \\
\hline & & & \multicolumn{2}{|c|}{ Group } & \multirow[b]{2}{*}{ Total } \\
\hline & & & $S$ & $T$ & \\
\hline \multirow[t]{4}{*}{ Functional improvement yes/no } & $\mathrm{n}$ & Count & 15 & 23 & 38 \\
\hline & & $\%$ within functional improvement yes/no & $39.5 \%$ & $60.5 \%$ & $100.0 \%$ \\
\hline & y & Count & 29 & 28 & 57 \\
\hline & & $\%$ within functional improvement yes/no & $50.9 \%$ & $49.1 \%$ & $100.0 \%$ \\
\hline \multirow[t]{2}{*}{ Total } & & Count & 44 & 51 & 95 \\
\hline & & $\%$ within functional improvement yes/no & $46.3 \%$ & $53.7 \%$ & $100.0 \%$ \\
\hline
\end{tabular}


Table 6: Comparison of time required for traditional repair and site-specific repair of POP

\begin{tabular}{llllllll}
\hline & \multicolumn{7}{c}{ Group statistics } \\
\hline & Group & $n$ & Mean & Standard deviation & Standard error mean & $t$-value & $p$-value \\
\hline Time in minutes for surgery & $\mathrm{T}$ & 51 & 77.31 & 16.948 & 2.373 & -1.33 & 0.186 \\
& $\mathrm{~S}$ & 44 & 81.34 & 14.916 & 2.275 & \\
\hline
\end{tabular}

Table 7: Comparison of success rate of traditional anterior colporrhaphy with our study

\begin{tabular}{|c|c|c|c|}
\hline Authors & Number & Follow-up & Success rate (\%) \\
\hline Stanton et $\mathrm{al}^{9}$ & 54 & 2 years & 85 \\
\hline Macer $^{10}$ & 109 & $5-20$ years & 80 \\
\hline Walter et al ${ }^{11}$ & 76 & 1.2 years & 100 \\
\hline Porges and Smilen ${ }^{12}$ & 388 & 2.6 years & 97 \\
\hline Colombo et $\mathrm{al}^{13}$ & 33 & 8-17 years & 97 \\
\hline Sand and Koduri ${ }^{4}$ & 70 & 1 year & 66 \\
\hline Weber and Walters ${ }^{3}$ & 57 & 23 months & 57 \\
\hline Our study & 51 & 6 months & 89.24 \\
\hline
\end{tabular}

better compared with traditional method of repair after 6 months, indicating that site-specific repair by vaginal route is a better operative procedure as compared with traditional method.

Though the size of our patient sample was small, the study was designed to minimize the confounding surgical factors including surgeon, type of surgery, and sites of prolapse. The study group was limited to women with combined prolapse of the three compartments (complex). The degree of prolapse is of less significance for an experienced surgeon. It is always better to do concomitant hysterectomy with apical prolapse.

Cystocele can be a paravaginal defect (lateral, displacement), midline defect (central, distention), or transverse defect (apical) when the pubocervical fascia separates from the vaginal cuff or uterosacral ligaments or both.

Kelly ${ }^{2}$ in 1913 described anterior colporrhaphy with the success rates of 80 to $100 \%$ in the management of cystoceles. As per evidence-based medicine, the results vary considerably for anterior colporrhaphy. In two randomized controlled trials, by Weber and Walters ${ }^{3}$ and Sand and Koduri, ${ }^{4}$ they reported less favorable outcomes with the anterior colporraphy, 42 and 57\% respectively.

In 1976, Richardson and Lyon ${ }^{5}$ modified the paravaginal repair originally described by White ${ }^{6}$ as early as 1912 . Studies have reported that the range of success rate for the paravaginal repair is 75 to $97 \%$. Though this technique can be done laparoscopically, no efficacy information is available. Prof Shull et al ${ }^{7}$ reported the safety and efficacy of the vaginal paravaginal repair in 1994, and various case series have reported success rates between 67 and $100 \%$. The high success rates have been associated with complications too. Mallipeddi et $\mathrm{al}^{8}$ in their case series of 45 patients reported one bilateral ureteric obstruction, one retropubic hematoma requiring surgery, and two
Table 8: Comparison of success rate of site-specific anterior repair with our study

\begin{tabular}{|c|c|c|c|}
\hline Authors & Number & Follow-up & Success rate (\%) \\
\hline White ${ }^{6}$ & 19 & 3 years & 100 \\
\hline Shull et al ${ }^{7}$ & 62 & 0.6 years & 67 \\
\hline Grody et al ${ }^{14}$ & 72 & $0.5-3$ years & 99 \\
\hline Elkins et $\mathrm{al}^{15}$ & 25 & $0.5-3$ years & 92 \\
\hline Mallipeddi et $\mathrm{al}^{8}$ & 45 & 0.6 years & 97 \\
\hline Young et $\mathrm{al}^{16}$ & 100 & 11 months & 78 \\
\hline Morse et al ${ }^{17}$ & 27 & 13 months & 54 \\
\hline Ours & 44 & 6 months & 90.91 \\
\hline
\end{tabular}

transfusions. Tables 7 and 8 show the comparison of various studies with ours.

The success rate of traditional anterior repair for anterior wall prolapse in our study correlates well with other studies.

Site-specific anterior repair was successful in $90.91 \%$ of women with POP when followed up for 6 months. This is in accordance with other studies. Totally, seven women underwent concomitant transobturator tape (TOT) surgery for associated stress urinary incontinence. A total of three women were in traditional repair group and four in site-specific repair group. Separate incision was taken for TOT when it was accompanied with anterior repair as studies mention that for any infection of colporrhaphy wound, it can lead to infection at the TOT site leading to failure of the procedure. We did not find any problem while doing concomitant TOT with anterior colporrhaphy taking separate incisions.

Rectoceles can be low, midvaginal, or high depending on the defect. High rectocele is the result of defects in the cardinal/uterosacral ligament complex. Midvaginal rectocele is caused by the weakening or detachment of the rectovaginal fascia from the arcus tendineus fasciae pelvis. Separation of the perineal body at the level of the rectovaginal fascia results in perineal descent or a low rectocele. Rectocele can be also according to the tearing portion of rectovaginal fascia: Lateral defect, central defect, apical defect, and perineal defect. Richardson identified various defects in rectovaginal fascia and directed repair at the specific sites of defect to produce a more anatomical repair. ${ }^{5}$ Studies on the site-specific defect repair have reported success rates in the range of 67 to $92 \%$ with good functional outcomes.

On following up the women with posterior repair by traditional method for 6 months, the success rate was $82.28 \%$, which is comparable with other studies (Table 9). 
Comparing Colporrhaphy, Colpoperineorrhaphy with Anterior and Posterior POP Repair

Table 9: Comparison of success rate of traditional posterior colpoperineorrhaphy with our study

\begin{tabular}{|c|c|c|c|}
\hline Author & Number & Follow-up & Success (\%) \\
\hline Kahn and Stanton ${ }^{18}$ & 171 & 43 months & 76 \\
\hline López et al $^{19}$ & 24 & 5 years & 91 \\
\hline Arnold et $\mathrm{al}^{20}$ & 29 & 4 years & 77 \\
\hline Mellgren et $\mathrm{al}^{21}$ & 25 & 1 year & 96 \\
\hline Maher 22 & 38 & 1 year & 97 \\
\hline Singh et $\mathrm{al}^{23}$ & 42 & 18 months & 92 \\
\hline Robinson et al ${ }^{24}$ & 34 & 41 months & 33 \\
\hline Our study & 51 & 6 months & 82.28 \\
\hline
\end{tabular}

The success rate of site-specific posterior repair was $86.37 \%$ when the women were followed up for 6 months (Table 10).

Concomitant hysterectomy at the time of POP repairs is the standard practice in most parts of the world despite the fact that descent of the uterus may be a result, not a cause of POP. However, concomitant hysterectomy is not an evidence-based practice. Suspension of the apex by an appropriate method should be considered at the time of each vaginal prolapse repair. In this study, concomitant hysterectomy was done in all women with vault suspension by McCall's method.

There are two totally different opinions about the treatment of POP. Von Theobald ${ }^{30}$ described POP as a disease of the connective tissue, and not an illness of the uterus, and hysterectomy does not cure the prolapse.

In the patient information leaflet of the British Society of Urogynaecology, there is information that the most common operation for uterine prolapse is a vaginal hysterectomy ${ }^{31}$ and $93 \%$ of the International Urogynecological Association members opted for this method. Prolapse repair for asymptomatic women at the time of other pelvic surgery is a reasonable option in women with advanced prolapse (stages 3 or 4) or risk factors for prolapse progression (e.g., concomitant hysterectomy, premenopausal status, obesity).

Concomitant hysterectomy increases the risk of some perioperative complications (e.g., mesh erosion). Repairs of only anterior or posterior prolapse have a higher failure rate than when these procedures are combined with apical prolapse repair. This was illustrated in the US national study of 2,756 women and found the following 10-year reoperation rates: Anterior repair vs combined anterior and apical repair (20.2 vs 11.6\%); anterior and posterior repair vs combined anterior, posterior, and apical repair (14.7 vs 10.2\%); and posterior repair vs combined posterior and apical repair (14.6 vs 12.9\%).

\section{CONCLUSION AND RECOMMENDATIONS}

Site-specific repair of torn native tissue has genuine curative potential, and success is attributable to site-specific
Table 10: Comparison of success rate of site-specific posterior repair with our study

\begin{tabular}{|c|c|c|c|}
\hline Author & Number & Follow-up & Success (\%) \\
\hline Abramov et al ${ }^{25}$ & 124 & 14 months & 67 \\
\hline Cundiff et $a^{26}$ & 69 & 12 months & 82 \\
\hline Kenton et $\mathrm{al}^{27}$ & 66 & 12 months & 77 \\
\hline Porter et $\mathrm{al}^{28}$ & 89 & 18 months & 82 \\
\hline Paraiso et $\mathrm{al}^{29}$ & 37 & 17 months & 78 \\
\hline Our study & 44 & 6 months & 86.37 \\
\hline
\end{tabular}

repair, rather than nonspecific scar formation by traditional method.

This article gives two guidelines for pelvic reconstructive surgeons:

(1) The pathogenesis of cystocele is fascial tears at top and side, as the vaginal suspensory hammock is avulsed from the pelvic sidewall during vaginal delivery.

Traditional anterior colporrhaphy is a quicker and simpler operation, but does not cure the actual sites of anatomic damage, though cystocele plication is helpful in a proportion of patients, presumably through the formation of a nonspecific scar plate beneath the vesical neck and bladder.

(2) Thus, it is important to properly quantify the repair to be done, whether anterior or posterior, and perform site-specific repair.

During posterior traditional repair, levator ani plication between the rectum and vagina has been implicated as a possible etiology for sexual dysfunction after standard posterior colporrhaphy.

So, omission of levator plication should be considered when unnecessary.

The knowledge about the reasons and mechanisms of POP is insufficient, which leads to completely different opinions about its treatment. Nevertheless, the amount of studies concerning the evaluation and the treatment of $\mathrm{POP}$ ensures that the quality of care provided to women with urogynecological problems is continuously increasing.

Anatomical as well as functional cure is important as it deals with concerned symptoms of vaginal bulge; anatomical POP-Q stage of I or O in the apical compartment is acceptable and is widely used as the optimum postoperative result.

\section{REFERENCES}

1. Weber AM, Abrams P, Brubaker L, Cundiff G, Davis G, Dmochowski RR, Fischer J, Hull T, Nygaard I, Weidner AC. The standardization of terminology for researchers in female pelvic floor disorders. Int Urogynecol J Pelvic Floor Dysfunct 2001;12(3):178-186.

2. Kelly HA. Incontinence of urine in women. Url Cutaneous 1913;17:291-293. 
3. Weber AM, Walters MD, Anterior colporrhaphy: a randomized trial of three surgical techniques. Am J Obstet Gynecol 2001 Dec;185(6):1299-1304.

4. Sand PK, Koduri S. Prospective randomized trial of polyglactin 910 mesh to prevent recurrence of cystoceles and rectoceles. Am J Obstet Gynecol 2001 Jun;184(7):1357-1356.

5. Richardson AC, Lyon JB. A new look at pelvic relaxation. Am J Obstet Gynecol 1976 Nov 1;126(5):568-573.

6. White GR. An anatomic operation for the cure of cystocele. Am J Obstet Dis Women Children 1912;65:286-290.

7. Shull BL, Benn SJ, Kuehl TJ. Surgical management of prolapse of the anterior vaginal segment: an analysis of support defects, operative morbidity, and anatomical outcome. Am J Obstet Gynecol 1994;171(6):1429-1439.

8. Mallipeddi PK, Steele AC, Kohlin N, Karram MM. Anatomic and functional outcome of vaginal paravaginal repair in the correction of anterior vaginal wall prolapse. Int Uorgynecol J Pelvic Floor Dysfunct 2001;12(2):83-88.

9. Stanton SL, Hilton P, Norton C. Clinical and urodynamic effects of anterior colporrhaphy and vaginal hysterectomy for prolapse with and without incontinence. Br J Obstet Gynaecol 1982 Jun;89(6):459-463.

10. Macer GA. Transabdominal repair of cystocele, a 20 year experience, compared with the traditional vaginal approach. Am J Obstet Gynecol 1978 May 15;131(2):203-207.

11. Walter S, Olesen KP, Hald T, Jensen HK, Pedersen PH. Urodynamic evaluation after vaginal repair and colposuspension. Br J Urol 1982 Aug;54(4):377-380.

12. Porges RF, Smilen SW. Long-term analysis of the surgical management of pelvic support defects. Am J Obstet Gynecol 1994 Dec;171(6):1518-1528.

13. Colombo M, Vitobello D, Proietti F, Milani R. Randomised comparison of Burch colposuspension versus anteriorcolporrhaphy in women with stress urinary incontinence and anterior vaginal wall prolapse. BJOG 2000 Apr;107(4):544-551.

14. Grody MH, Nyirjesy P, Kelley LM, Millar ML. Paraurethral fascial sling urethropexy and vaginal paravaginal defects cystopexy in the correction of urethrovesical prolapse. Int Urogynecol J Pelvic Flor Dystunct 1995 Mar;6(2):80-85.

15. Elkins TE, Chesson RR, Videla F, Menefee S, Yordan R, Barksdale PA. Transvaginal paravaginal repair: a useful adjunctive procedure at pelvic relaxation surgery. J Pelvic Surg 2000 Jan;6:11-15.

16. Young SB, Daman JJ, Bony LG. Vaginal paravaginal repair: one-year outcomes. Am J Obstet Gynecol 2001 Dec;185(6): 1360-1366; discussion 1366-1367.
17. Morse AN, O’Dell KK, Howard AE, Baker SP, Aronson MP, Young SB. Midline anterior repair alone vs anterior repair plus vaginal paravaginal repair: a comparison of anatomic and quality of life outcomes. Int Urogynecol J Pelvic Floor Dysfunct 2007 Mar;18(3):245-249.

18. Kahn MA, Stanton SL. Posterior colporrhaphy: its effects on bowel and sexual function. Br J Obstet Gynaecol 1997 Jan;104(1):82-86.

19. López A, Anzén B, Bremmer S, Mellgren A, Nilsson BY, Zetterström J, Holmström B. Durability of success after rectocele repair. Int Urogynecol J Pelvic Floor Dystunct 2001; 12(2):97-103.

20. Arnold MW, Stewart WR, Aguilar PS. Rectocele repair. Four years' experience. Dis Colon Rectum 1990 Aug;33(8):684-687.

21. Mellgren A, Anzén B, Nilsson BY, Johansson C, Dolk A, Gillgren $\mathrm{P}$, Bremmer $\mathrm{S}$, Holmström B. Results of rectocele repair. A prospective study. Dis Colon Rectum 1995 Jan;38(1):7-13.

22. Maher C. Midline rectovaginal fascial plication for repair of rectocele and obstructed defecation. Obstet Gynecol 2004 Oct;104(4):685-689.

23. Singh K, Cortes E, Reid WM. Evaluation of the fascial technique for surgical repair of isolated posterior vaginal wall prolapse. Obstet Gynecol 2003 Feb;101(2):320-324.

24. Robinson DW, Cardozo L, Bidmead J, Balmforth J. Fascial posterior colpoperineorrhaphy: a five year follow-up study. J Pelvic Med Surg 2003;9(6):279-283.

25. Abramov Y, Gandhi S, Goldberg RP, Botros SM, Kwon C, Sand PK. Site-specific rectocele pair compared with standard posterior colporrhaphy. Obstet Gynecol 2005 Feb;105(2): 314-318.

26. Cundiff GW, Weidner AC, Visco AG, Addison WA, Bump RC. An anatomic and function alasessment of the discrete defect rectocele repair. Am J Obstet Dis Women Children 1998 Dec;179(6 Pt 1):1451-1456; discussion 1456-1457.

27. Kenton K, Shott S, Brubaker L. Outcome after rectovaginal fascia reattachment for rectocele repair. Am J Obstet Gynecol 1999 Dec;181(6):1360-1363.

28. Porter WE, Steele A, Walsh P, Kohli N, Karram MM. The anatomic and functional outcomes of defect-specific rectocele repairs. Am J Obstet Gynecol 1999 Dec;181(6):1353-1358.

29. Paraiso MF, Barber MD, Muir TW. Rectocele repair: a randomized trial of three surgical techniques including graft augmentation. Am J Obstet Gynecol 2006 Dec;195(6):1762-1771.

30. Von Theobald P. Place of mesh in vaginal surgery, including its removal and revision. Best Pract Res Clin Obstet Gynaecol 2011 Apr;25(2):197-203.

31. Available from http://bsug.org.uk/patient-information.php. 